\title{
Treatment strategies for professional sexual misconduct
}

\author{
Marc Ravart PhD , Pierre Assalian MD
}

\author{
M Ravart, P Assalian. Treatment strategies for professional \\ sexual misconduct. J Sex Reprod Med 2003;3(3):93-97.
}

The therapeutic process in the clinical and social management of professional sexual misconduct is complex and complicated by legal reports and procedures, the involvement of professional association review boards and the negative impact of the media. Crisis interventions and supportive individual, couple and family counseling are frequently necessary before therapy can more directly focus on the sexual misconduct. Offenders usually hope to maintain, or expect to resume, their professional practice, increasing the use of deception, denial of problems and avoidance of self-revelation and self-examination. Through the course of treatment, reintegration into their professional practice may or may not be recommended. If reintegration is feasible, modification of their professional roles may also be preferable and recommended. However, prognosis is usually considered better than with most other types of sex offenders. A major focus of this anaylsis is to provide a description of current treatment procedures for professional sexual misconduct. A brief review of the immediate and deeper causes of this sexual problem will also be presented. When reintegration in the workplace is feasible, issues concerning posttreatment maintenance planning, identification of the victim pool and the establishment of preventive measures and safeguards will be reviewed.

Key Words: Clinical management; Professional sexual misconduct; Relapse-prevention; Treatment strategies

\section{Les stratégies de traitement en cas d'inconduite sexuelle professionnelle}

RÉSUMÉ : Le processus thérapeutique dans la prise en charge clinique et sociale d'une inconduite sexuelle professionnelle est complexe et compliqué par les rapports et les poursuites juridiques, la participation des commissions d'examen des associations professionnelles et les répercussions négatives des médias. Des interventions d'urgence et un counseling à l'individu, au couple et à la famille s'imposent souvent avant que la thérapie puisse porter plus directement sur l'inconduite sexuelle. D'ordinaire, les délinquants désirent conserver leur pratique professionnelle ou prévoient la reprendre, ce qui accroît les tromperies, le déni des problèmes et l'évitement d'une révélation de soi et d'un auto-examen. Pendant le traitement, la réintégration à la pratique professionnelle peut ou non être recommande. Si la réintégration est possible, la modification des rôles professionnels peut également être préférable et recommandée. Cependant, le pronostic est souvent considéré comme meilleur qu'avec la plupart des autres types de délinquants sexuels. La présente analyse vise principalement à décrire les modalités de traitement en cas d'inconduite professionnelle. Un bref examen des causes immédiates et plus profondes de ce problème sexuel est également présenté. Lorsque la réintégration au milieu de travail est possible, les questions relatives à la planification de cette réintégration après le traitement, l'identification au groupe des victimes et la mise en œuvre de mesures préventives et de protection sont examinées.
$\mathrm{T}$ he therapeutic process in the clinical and social management of professional sexual misconduct is complex and complicated by legal reports and procedures, the involvement of professional association review boards and the negative impact of the media. Crisis interventions and supportive individual, couple and family counseling are frequently necessary before therapy can more directly focus on the sexual misconduct. Offenders usually hope to maintain, or expect to resume, their professional practice, increasing the use of deception, denial of problems and avoidance of self-revelation and selfexamination. Through the course of treatment, reintegration of their professional practice may or may not be recommended. If reintegration is feasible, modification of their professional roles may also be preferable and recommended. However, prognosis is usually considered better than with most other types of sex offenders. A major focus of this analysis is to provide a description of current treatment procedures for professional sexual misconduct. A brief review of the immediate and deeper causes of this sexual problem will also be presented. When reintegration in the workplace is feasible, issues concerning post-treatment maintenance planning, identification of the victim pool and the establishment of preventive measures and safeguards will be reviewed.

\section{Treatment strategies for professional sexual misconduct}

The therapeutic management of professional sexual misconduct is quite straightforward. After the completion of a comprehensive evaluation, the treatment process essentially consists of helping the offender understand his behaviour, addressing issues and problems associated with professional misconduct, increasing victim empathy and implementing relapse-prevention strategies and safeguards. Promisingly, multimodal, cognitive-behavioural and integrative treatment programs have been elaborated to meet the special needs of this clinical population (1-9). For preventive

\footnotetext{
Human Sexuality Unit, Montreal General Hospital, Quebec

Correspondence: Dr Marc Ravart, 600 rue Sherbrooke Est, Suite 301, Montréal, Québec H2L 1K1. Telephone 514-844-3363, fax 514-844-2397,e-mail marc.ravart@staff.mcgill.ca
} 
purposes, educational programs have also been established for health and mental health professionals who cross sexual boundaries $(10,11)$. This paper presents an overview of current treatment procedures in the management of professional sexual misconduct.

Sealy (9) categorized different boundary violations that should be considered in the risk management of professional sexual misconduct. These categories include: ethics boundaries (eg, violations that occur outside of professional relationships but cross the boundaries set by the ethics and principles of the profession, such as a physician who solicits sexual contact with a minor on his home computer); institutional boundaries (eg, violations of the institution where the subject works, such as a physician being caught privately downloading from the Internet and viewing pornography on a hospital computer); and professional interpersonal boundaries (eg, violations involving the crossing of sexual professional/interpersonal boundaries, such as a physician who develops sexual affairs and relations with patients, nurses, medical staff, students, trainees, supervisees, drug company representatives or any other people who relate to the subject in the context of his profession).

Based on the evaluation, reintegration of offenders into their professional practice may or may not be recommended. Recommendations consider the nature of the offense, the offender's insight and remorse, degree of psychopathology and overall occupational functioning, all of which play a role in the professional's chances for rehabilitation within the limits of community safety. For many, modification of their professional roles may be indicated, while most receive considerations pertaining to treatment recommendations before and/or after they resume their professional practice.

Prognosis is usually considered better and treatment is less complicated than with most sex offenders and paraphiliacs. The best prognosis for positive treatment outcome corresponds to the more uninformed, naive professional who may be mildly neurotic and lacking in appropriate training or supervision. A guarded prognosis is attributed to the more severely neurotic professional who chronically feels inadequate, dependent and driven toward recognition and success. A poor prognosis is more warranted in cases with marked personality and impulse control disorders, including psychotic and borderline conditions as evidenced by poor social judgment and impaired reality testing. Finally, the worst prognosis is given to individuals with malignant psychopathic, antisocial or sadistic personalities wherein deliberate abuse is noted among multiple victims.

\section{Etiology}

Etiological explanations on the ethical failures of professionals are diverse and cannot be explained only by psychiatric diagnoses (8). In most cases, both immediate (eg, depressed states, alcohol/substance abuse, erotic countertransference, sexual preoccupation and fantasies, dealing with a seductive client/patient who presents sexually compulsive dynamics which evoke erotically charged interactions) and deeper causes (eg, narcissistic need for validation, unresolved reenactment of childhood traumas, dependency issues and problems with solitude, intimacy and boundaries) play a role in rendering the professional vulnerable to act out sexually. Offenders may report falling in love with their patients, having felt vulnerable, needy or lonely before the acting out period. Unsatisfying and troubled personal relationships may also increase the professional's vulnerability to act out sexually with a client/patient. Lybarger (12) suggests sexual compulsions and/or addictions may be a major cause of professional sexual misconduct, noting that $86 \%$ of sexual addicts surveyed have reported sexual acting-out behaviours in the workplace. Sealy (9) reports sexual addictions are present in over $50 \%$ of professionals alleged with sexual impropriety. Levine et al (8) found that $26 \%$ of their sample of professionals $(n=31)$ presented comorbid diagnoses of paraphilia, while another $29 \%$ evidenced sexual compulsions and $58 \%$ presented Axis II personality disorders.

Many specialists note the role of cognitive distortions in facilitating the sexual misconduct $(3,8,9,13)$. Gartrell and collegues (13) found that repeat offenders believed in the therapeutic value of sexual relations with patients as a form of corrective emotional experience geared toward healing and/or promoting change in the patient. Gabbard (14) referred to the works of Stoller (15) in an attempt to explain why some psychotherapists destructively sexually act out and cannot contain and constructively process normal erotic transference and countertransference reactions. Stoller's (15) victim-victor theory explains how sexual deviations and compulsions may develop through a psychodynamic process of turning childhood traumas into adulthood triumphs. Gabbard (14) suggests professionals may sexually act out to achieve and feel powerful and strong in their erotic lives, thereby neutralizing and undoing chronic feelings of inadequacy, humiliation and anxiety about their masculinity.

Adams (4) describes professional sexual misconduct and harassment as resulting from repetitive, escalating cycles of childhood trauma re-enactment and sexual compulsivity, stemming from unresolved feelings and issues related to disturbed family and relational attachment and bonding experiences. These traumas unconsciously re-emerge, and are projected and acted out in relationships in which a power differential exists. Before the acting out process, the offender usually experiences low self-esteem, guilt, depression and shame. The professional may use sex within the workplace to master feelings of neglect, abandonment, anger and insecurity. The behaviour increases a sense of excitement and heightened well-being and temporarily helps modulate anxiety. Adams (4) argues sexual misconduct behaviour is often one aspect of a repetitive pattern of destructive behaviours, with a power differential at its core. Professionals who cross sexual boundaries are often entangled in a sexual addictive system and they seem to evidence great difficulties to control their impulses.

\section{Typology}

Sealy (9) considers three severity levels of professional sexual misconduct that should be considered in the treatment plan: sexual impropriety (eg, violations which include inappropriate sexual remarks and comments); sexual transgressions (eg, violations which include inappropriate touching); and sexual violations (eg, violations which include sexual relationships).

To further help understand the forces and motives underlying professional sexual misconduct, Irons and Schneider (7, 16) categorized a group of 137 professionals into an archetypal classification system. This classification system helps in predicting response to treatment and can provide analytical information about the subject's object relations and psychosexual/social functioning that can be addressed and examined in the subject's therapy. The six categories include: The Naive Prince ( $8 \%$ of the sample); The Wounded Warrior 
(22\%); The Self-Serving Martyr (24\%); The False Lover (19\%); The Dark King (12\%); and The Wild Card (15\%).

The Naive Prince includes professionals who feel invulnerable and powerful with their new professional status. They develop a privileged relationship with one or more patients or clients, and a 'blurring' of appropriate professional boundaries leads to sexual misconduct. The subject is usually psychologically healthy, with limited neurotic conflict and feels guilty and remorseful, realizing he violated ethical standards. These offenders respond well to education, counseling and monitoring, and there is usually a good prognosis.

The Wounded Warrior describes offenders who have attempted to heal professional demands, internal struggles and childhood/adolescent wounds by becoming sexually involved with one or more patients or clients, but this temporary escape only produces additional guilt and shame. The subject is generally psychologically healthy, with limited neurotic conflicts and may have situational depression. Prognosis is quite good following confrontation, boundary education, counseling and monitoring. Professional re-entry is possible if he remains in long term treatment.

The Self-Serving Martyr refers to professionals who have, in mid-to-late career, become isolated, resentful and angry at the lack of appreciation of the personal and family sacrifices they have made for their career. The sexual misconduct helps relieve their perceived suffering. The professional generally presents significant neurotic conflicts, and addictive disorders are common. A personality disorder or predominant pathological character traits may be seen, and they are often withdrawn and dysthymic. Withdrawal from practice and inpatient treatment is often required. Professional re-entry, when feasible, is often delayed and subsequently restricted.

The False Lover describes a charming, creative and energetic person who lives a life of intensity and continual high drama. Impulse control is a major concern, and the sexual misconduct fulfills a need for excitement and high-risk behaviours. Personality disorders are usually present in this group, and is often the primary diagnosis, with frequent narcissistic, histrionic and dependent features. Withdrawal from practice and intensive treatment are required, usually in an inpatient setting. Professional re-entry is possible, but not assured.

The Dark King is driven by grandiosity and a desire to control and dominate. This professional possesses a rich and pathological array of narcissistic, antisocial/psychopathic, borderline and schizotypal personality disorders, often with superior intellectual gifts. Character pathology is often severe, and most are unable to return to previous professional practice.

Finally, The Wild Card describes those offenders who have a major Axis I disorder, most commonly major depression with psychotic features, bipolar affective disorder, atypical psychosis, dissociative disorder and organic mental disorders. Sexual acting out occurs when the primary disorder is not managed, and is often associated with poor social judgment and blurred professional boundaries. The subject usually does not present a paraphilic or nonparaphilic sexual disorder, but rather, the sexual misconduct is associated with disinhibition, lack of impulse control, cognitive distortion, dissociative state, psychotic thinking or dementia.

Irons and Schneider $(7,16)$ report the last four categories strongly comprise of professionals with obsessive-compulsive sexual disorders. With appropriate assessment and confrontation, inpatient and/or intensive outpatient treatment, long term follow-ups, monitoring and appropriate work modifications and contractual provisions, most professionals in the first four categories can usually be rehabilitated and should be able to reenter some type of professional practice.

\section{TREATMENT STRATEGIES FOR PROFESSIONAL SEXUAL MISCONDUCT}

The comprehensive treatment program presented focuses on improving psychological and occupational functioning to prevent recidivism of sexual misconduct.

\section{Psychological functioning}

Treatment focus includes: dynamic understanding of the immediate and deeper issues that are directly and indirectly associated with the sexual misconduct; awareness of associated problems and consequences on the victims; identification of associated cognitive distortions; examination and working through of personal and relational problems associated to the misconduct.

\section{Occupational functioning}

The offender's occupational functioning is evaluated through consideration of his overall psychological and psychosocial functioning, and capacity to show good judgment and meet the skills and demands of his profession. Treatment issues to improve occupational functioning include: establishment of appropriate, healthy professional relationships/boundaries with all their patients, clients, coworkers and subordinates; development of efficient short and long-term strategies to prevent recidivism; and implementation of a prevention plan within the professional practice.

\section{Treatment process}

The professional's trust in the evaluation and therapeutic process may be difficult to establish and assess, considering the professional may be uncertain if it is in his best interest to totally reveal himself and tell the truth about his misconduct and problematic traits and behaviours, especially when a treatment summary report is expected by the courts or subject's professional board. The treatment provider must work on building a treatment alliance, identify and bypass the professional's defenses, confront his resistance, avoidance, minimization, lies and associated cognitive distortions. Given the context of treatment, keep in mind the professional may make efforts to appear adequate, in control and in a more favorable light.

Overall, treatment, follow-up, and monitoring is generally a three to five year process. The thematic issues covered in therapy and treatment strategies used to help sexual compulsives control their behaviour may also be applicable and integrated in the treatment of professional sexual misconduct (7,9,17-19). Twelve-step programs such as Alcoholics Anonymous, Narcotics Anonymous and Sexaholics Anonymous are not treatment programs, but can be complimentary for additional emotional, social, and moral support. Sealy (9) notes that offenders may resist treatment for various reasons: they are used to be in control; they are afraid and vulnerable to career loss; grandiosity; intellectualization; discounting they have emotional needs; fear of self-disclosure; and manipulation of rules. 
Treatment first addresses the need to control and contain the inappropriate sexual behaviour. Offenders examine their feelings, problematic attitude and behaviour. High risk situations are identified and eliminated. Following cognitivebehavioural and relapse-prevention procedures, such as those described by Abel and Osborn (3), the subject learns strategies of self-control and techniques on how to identify and break the chain of events leading to the sexual misconduct. Core emotional problems are dealt with by confronting dysfunctional thoughts and cognitive distortions (irrational beliefs, rationalizations, justifications and attributions), employing basic cognitive-restructuring interventions to negative cognitions and emotions associated to the sexual misconduct. The planning of the behaviour and the covering-up process should also be examined. Subjects may be required to do their own bibliography and provide a literature review on the problem. They are also required to provide a definition of healthy versus unhealthy professional relations boundaries.

Victim empathy can be increased by helping the professional explore short and long term potential negative consequences on the victim and himself. Psychotherapeutic procedures of role-play and imagined letters to and from the victim written by the subject can also increase victim empathy. It is important to bring the professional to examine himself and his interactions with the victim(s). Factors to examine include how the professional was possibly perceived before, during and after the misconduct and how he abused his power and authority to seduce and manipulate his victim(s). Characteristics of the victim's personality, life situation and presenting problem should also be examined with the professional to better understand how the victim was vulnerable to seduction and sexual exploitation. Conversely, this analysis will further help identify vulnerability issues in the professional that should be considered in the clinical management of his case.

Pharmacological applications should be considered, especially sustained serotonin reuptake inhibitors, which help treat underlying sexual obsessions and compulsivity, paraphilic interests and associated mood disorders $(18,20)$. Insightoriented, sexo-analytical therapeutic techniques can also promote further understanding into the the deeper issues of the sexual misconduct $(6,21)$. Therapeutic work should address the subject's self-destructiveness, personality deficits and object relations.

When reintegration in the workplace is feasible and recommended, the treatment providers may need to collaborate with the organizational board to assess and devise a method to monitor if necessary, the subject's professional workplace. Supervision of professional practice, additional training and the use of educational programs as continuing education courses should be considered before and after the re-entry process. For re-entry into their practice, the professional board of the offender should examine the appropriateness of the practice setting. Appropriate professional practice style and capacity to establish and maintain professional boundaries must be demonstrated.

The re-entry process in the workplace should follow a relapse-prevention approach. Significant coworkers with whom the subject works should be alerted in a manner that does not further stigmatize the subject by others who are or who are not aware of the subject's problem. There is usually a strong need by the professional and the employer to maintain a low profile. To protect future victims, contractual provisions for re-entry may be required and should be established by the subject's professional board, based on the nature of the case. For example, a physician who inappropriately touched the genitals of several female patients will thereafter require the presence of a chaperon for examining all female patients, or may no longer be allowed to have female patients of a specified age group.

The professional must demonstrate a collaborative approach to rebuild confidence with his professional board and the community. How has the offender adjusted to his presenting problem, and what changes have occurred following the misconduct? Have high-risk clients/patients been defined and restricted? Has the professional's mental and physical health improved or deteriorated? Have the events activated a positive change in the offender's life (eg, abstinence from alcohol/drugs, more committed to family)? Has the offender implicated himself in the therapeutic process, does he take full responsibility for his actions and is he critical of his behaviour? What is the treatment status and overall outcome?

Proper safeguards should be erected to assure the subject's professional practice is modified, according to the case characteristics and victim pool considered most at risk. A bill or listing of client/patient rights can be given to each person who consults the professional, in the format of a pamphlet following their first contact. This pamphlet can describe the specifics and limitations of the professional's practice, provide a definition of the professional boundaries, and describe client/patient rights. Anonymous surveys could also be devised and given to clients/patients to monitor the subject's professionalism. As part of their healing process and devotion to build a positive professional reputation, offenders can find ways to symbolically repair their behaviour. For example, the professional can financially help or give volunteer time to a victim-oriented organization, or can give a presentation at a conference of his professional association to discuss the problem of sexual misconduct, with the attitude that his talk can help alert potential offenders and prevent sexual misconduct behaviours. Maintenance psychotherapy should continue, as per the subject's personal needs and therapist recommendations. Long term reassessments of the subject's psychological and occupational status are desirable.

\section{REFERENCES}

1. Abel GG. Sexual misconduct by physicians: Evaluation and treatment. Course presentation given at the Department of psychiatry, Montreal General Hospital, Montreal, Canada, 1994.

2. Abel GG, Barrett DH, Gardos BA. Sexual misconduct by physicians. J Med Assoc Georgia 1992;81:237-46.

3. Abel GG, Osborn CA. Cognitive-behavioural treatment of sexual misconduct. In: JD Bloom, CC Nadelson, MT Notman ,eds. Physician Sexual Misconduct. Washington: American Psychiatric Press, 1999:224-46.

4. Adams KM. Sexual harassment as cycles of trauma reenactment and sexual compulsivity. Sex Addict Compuls 1999;6:177-93.

5. Bloom JD, Nadelson, MT Notman, eds. Physician sexual misconduct. Washington: American Psychiatric Press, 1999.

6. Gabbard GO. Psychodynamic approaches to physician sexual misconduct. In: JD Bloom, CC Nadelson, MT Notman, eds. Physician Sexual Misconduct. Washington: American Psychiatric Press, 1999:205-23.

7. Irons R, Schneider J. The wounded healer: Addiction-sensitive approach to the sexually exploitive professional. New Jersey: Jason Aronson, 1999.

8. Levine SB, Risen CB, Althof SE. Professionals who sexually offend: 
Evaluation procedures and preliminary findings. J Sex Marit Ther 1994;20:288-302.

9. Sealy JR. Physician sexual misconduct. Sex Addict Compuls 2002;9:97-111.

10. Spickard A, Swiggart WH, Manley G, Dodd D. A continuing education course for physicians who cross sexual boundaries. Sex Addict Compuls,2002;9:33-42.

11. Swiggart W H, StarrK, Finlayson R, Spickard A Jr. Sexual boundaries and physicians: Overview and educational approach to the problem. Sex Addict Compuls 2002;9:139-48.

12. Lybarger JS. Sexual addiction: A hidden factor in sexual harassment. Sex Addict Compuls 1997;4:77-90.

13. Gartrell N, Herman J, Olarte S, Feldstein M, Localio R.

Psychiatrist-patient sexual contact: Results of a national survey. I. Prevalence. Am J Psych, 1986;143:1126-30.

14. Gabbard GO, ed. Sexual Exploitation in Professional Relationships. Washington: American Psychiatric Press, 1989.

15. Stoller RJ. Sexual Excitement: Dynamics of Erotic Life. New York:
Pantheon, 1979.

16. Irons R, Schneider J. Sexual addiction: Significant factor in sexual exploitation by health care professionals. SexAddict Compuls 1994;1:198-214

17. Adams KM, Robinson DW. Shame reduction, affect regulation, and sexual boundary development: Essential building blocks of sexual addiction treatment. Sex Addict Compuls 2002;8:23-44.

18. Assalian P, Ravart M. Compulsive sexual behaviour: Etiology, clinical manifestations and pharmacological treatment. Can J Hum Sex 1993;2:221-6.

19. Carnes P. Don't Call it Love: Recovery From Sexual Addiction. New York: Bantam, 1991

20. Sealy JR. Psychopharmacologic intervention in addictive sexual behavior. Sex Addict Compuls 1995;2:257-76.

21. Ravart M, Côté H. Sexoanalysis: A new insight-oriented treatment approach for sexual disorders. J Sex Marit Ther 1992;18:128-40. 